Bettylou K. Mokriski mD, Andrew M. Malinow MD, William C. Gray MD, William J. McGuinn MD

\title{
Topical nasopharyngeal anaesthesia with vasoconstriction in preeclampsia-eclampsia
}

\begin{abstract}
We report the case of a 38-year-old eclamptic patient undurgoing emergency Caesarean section who required awake nasotracheal intubation because of her massively swollen and lacerated tongue, Vasoconstriction, in addition to topical anaesthesia, was required due to thrombocytopaenia. The use of three per cent lidocaine with 0.125 per cent phenylephrine for araesthesia and vasoconstriction is described with successful maternal and neonatal outcome.
\end{abstract}

Awake nasotracheal intubation after adequate topical anaesthesia and constriction of the nasal mucosa is suggested for pregnant patients in whom difficult or impossible direct laryngoscopy is anticipated. 'However, there is no published information on the appropriate method of topical nasopharyngeal anaesthesia in the eclamptic patient.

\section{Case report}

A 38-year-old, $91 \mathrm{~kg}$ gravida 2, para 1 was transferred to University Hospital after treatment in a community hospital emergency room for a grand mal seizure. Systemic arterial blood pressure was $200130 \mathrm{mmHg}$. Urinalysis revealed $>300 \mathrm{mg} \cdot \mathrm{dl}^{-1}$ protein. A previously unsuspected pregnancy was shown by ultrasound examination (26.5 weeks gestation). After the diagnosis of eclampsia was made, intravenous magnesium sulfate therapy was begun.

On arrival, the patient was drowsy but responsive to verbal stimuli. Systemic arterial blood pressure was

\section{Key words}

ANAESTHESIA: obstetrical; ANAESTHETICS, LOCAL: lidocaine; PREGNANCY: eclampsia; INTUBATION: tracheal; SYMPATHETIC NER VOUS SYSTEM, VASOCONSTRICToRs: phenylephrine.

From the Department Anesthesiology, University of Maryland Medical School, 22 S. Greene Street, Baltimore, Maryland 21201.

Address Correspundence to: Dr. Mokriski.
$220 / 140 \mathrm{mmHg}$ and the heart rate 88 beats per minute. Physical examination revealed an obese gravida with a short, thick neck. There was a tongue laceration, secondary to the seizure. It was possible to visualize the posterior pharynx. Laboratory studies revealed: haemoglobin 14 $\mathrm{g} \cdot \mathrm{dl}^{-1}$; platelet count of $59,000 \cdot \mathrm{ml}^{-1}$; and normal coagulation studies.

Continuous maternal intra-arterial pressure monitoring was instituted. Intravenous magnesium sulfate therapy was continued. A 0.01 per cent hydralazine IV infusion was titrated to maintain a maternal systemic arterial diastolic blood pressure between 105-1 $10 \mathrm{mmHg}$. Central venous pressure measured via the right internal jugular vein was $7 \mathrm{mmHg}$. Urinary output was $50-200$ $\mathrm{ml} \cdot \mathrm{hr}^{-1}$. Lactated Ringer's solution was infused IV at 50 $\mathrm{ml} \cdot \mathrm{hr}^{-1}$

Six hours later the matemal platelet count had fallen to $38,000 \cdot \mathrm{ml}^{-1}$. The decision was made to proceed with Caesarean section because of worsening eclampsia. Examination of the mouth and airway now revealed massive swelling of the tongue which restricted mouth closure. It was not possible to visualize the soft palate.

The patient was taken to the delivery room and positioned supine with left uterine displacement. Mean maternal systemic arterial blood pressure was $140 \mathrm{mmHg}$. An IV infusion of 0.1 per cent trimethaphan was started to maintain the maternal systemic arterial diastolic pressure between $95-105 \mathrm{mmHg}$. Topical nasal anaesthesia was achieved with $4 \mathrm{ml}$ of a 3.0 per cent lidocaine with 0.125 per cent phenylephrine solution (prepared with $3 \mathrm{ml}$ of four per cent lidocaine, $0.5 \mathrm{ml}$ of one per cent phenylephrine and $0.5 \mathrm{ml}$ of normal saline solution) applied to the nasal and nasopharyngeal mucosa with cotton tipped applicators. There were no changes detected in the fetal heart rate. Maternal blood pressure was 150-160/95-100 $\mathrm{mmHg}$. The heart rate was 72 beats $\mathrm{min}^{-1}$. Central venous pressure was $5 \mathrm{mmHg}$. The patient was prepared for surgery, An otolaryngologist was immediately available to assist in emergency airway management. Awake fiberoptic (Olympus $\mathrm{LFl}$ ) nasotracheal intubation with a 6.0 ID Portex tracheal tube was achieved with great difficulty, due to oropharyngeal swelling and glottic 
oedema. During endoscopy and placement of the endotracheal tube, maternal blood pressure remained at 150 $160 / 95-100 \mathrm{~mm} H \mathrm{Hg}$, with no change in dose requirements of antihypertensive agents. No additional topical anaesthesia was required during the intubation. General anaesthesia was induced immediately after intubation with IV thiamylal $4 \mathrm{mg} \cdot \mathrm{kg}^{-1}$.

Surgery then commenced. Induction to delivery time was five minutes with an uterine incision to delivery time of 60 seconds. A premature female child with Apgar scores of 1 and 6 at one and five minutes respectively was delivered. Oniy umbilical venous blood $(\mathrm{pH} 7.31)$ was obtained. The trimethaphan infusion was discontinued as intraoperatively the mean maternal systemic arterial blood pressure ranged between 75-100 mmHg. Moderate bleeding from the traumatized nasal mucosa was controlled easily by placement of nasal packing. Surgical haemostasis was judged adequate and the estimated surgical blood loss was $600 \mathrm{ml}$. The patient was transported to the postanaesthesia care unit intubated but spontaneously ventilating. Postoperatively the swelling of the tongue markedly decreased and the patient was extubated 24 hours after delivery without difficulty. The nasal packing was removed and there was no further bleeding.

\section{Discussion}

Awake nasotracheal intubation done after thorough topical anaesthesia can minimize the haemodynamic effects of intubation in sedated nonpregnant patients. ${ }^{2}$ However, sedation is best avoided in the pregnant paticnt due to the possibility of neonatal depression or maternal aspiration. The haemodynamic effects of topical anaesthesia and awake intubation are not well described in pregnant patients and have not been investigated in preeclampticeclamptic patients. Matemal systemic arterial pressures must be controlled in eclampsia to avoid end-organ damage. ${ }^{3}$ The use of a vasoconstrictor, despite the risk of decreasing uteroplacental perfusion, was necessary to limit epistaxis in this thrombocytopaenic patient.

A four per cent cocaine solution is widely used for topical anaesthesia in nonpregnant patients. Despite vasoconstriction, cocaine is absorbed from the nasal mucosa. ${ }^{4}$ Recent reports though have related nasal cocaine absorption to decreased uterine blood flow, ${ }^{5-7}$ The administration of an intravenous $1.4 \mathrm{mg} \cdot \mathrm{kg}^{-1}$ dose of cocaine to pregnant ewes has been shown to achieve blood concentrations similar to those seen after intra-nasal use in bumans. ${ }^{5}$ Within one minute after administration, uterine blood flow bas been shown to decrease by 40 per cent. ${ }^{5}$ Similar decreases in uterine blood flow occur after 0.5 $\mathrm{mg} \cdot \mathrm{kg}^{-1}$ and $1 \mathrm{mg} \cdot \mathrm{kg}^{-1}$ intravenous cocaine doses, concomitant with increases in mean arterial blood pres- sure. ${ }^{6}$ Fetal heart rate was shown to increase 10 to 30 minutes after intravenous administration of 1 and 2 $\mathrm{mg} \cdot \mathrm{kg}^{-1}$ cocaine doses to pregnant ewes. ${ }^{7}$ We therefore felt that the use of cocaine to obtain anaesthesia and vasoconstriction would risk severe decreases in uteroplacental perfusion in this pregnancy.

The use of aerosolized lidocaine-phenylephrine solutions for nasopharyngeal anaesthesia and vasoconstriction satisfactorily substitutes for four per cent cocaine in nonpregnant patients. ${ }^{8}$ There are no differences in heart rate and mean arterial pressurc during administration between the two regimens. Mean arterial pressure after intubation increases less with the combination of lidocaine-phenylephrine when compared to cocaine or phenylephrine alone $(2.3 \mathrm{mmHg}$ decrease vs $6.2 \mathrm{mmHg}$ and $8.5 \mathrm{mmHg}$ increase, respectively). ${ }^{8}$ Additionally, there is no difference in the incidence or severity of epistaxis.

Phenylephrine does cause uterine artery vasoconstriction and decreases in uterine blood flow. ${ }^{9}$ Although both cocaine and phenylephrine lead to decreased uterine blood flow, we speculate that the lidocaine-phenylephrine combination might increase the systemic blood pressure less than cocaine. The evidence in nonpregnant and normotensive patients suggests that the lidocainephenylephrine combination gives important haemodynamic stability. ${ }^{8}$ Thus, we chose the lidocaine-phenylephrine combination easily prepared with four per cent lidocaine, onc per cent phenylephrine and normal saline solution. There were no changes in fetal heart rate detected after the administration of three per cent lidocaine and 0.125 per cent phenylephrine. The acid-base status of the infant was normal upon delivery.

In conclusion, necessary awake intubation in preeclampsia-eclampsia presents the obstetric anaesthetist with a difficult phamacologic dilemma. Intubation must be performed without the commonly used sedation with adequate topical nasopharyngeal anaesthesia. Prevention of severe epistaxis requires vasoconstriction with agents which could lead to decreased uteroplacental perfusion. The lidocaine-phenylephrine combination used in this patient maximized haemodynamic stability and uteroplacental perfusion while giving adequate topical anaesthesia and vasoconstriction. This technique might also be applied to any patient requiring awake nasotracheal intubation. 


\section{References}

1 Cheek TG, Gursche BB. Pulmonary aspiration of gastric contents. In: Shnider SM, Levinson G. (Eds). Anesthesia for Obstetrics. Baltimore: Williams and Wilkins, 1987: 309.

2 Ovassapian A, Veiich SJ, Dykes MHM, Brunner EE. Blood pressure and heart rate changes during awake fiberoptic nasotracheal intubation. Anesth Analg 1983; 62: $951-4$.

3 Hodgkirson $R$, Husain FJ, Hayashi RH. Systemic and pulmonary blood pressure during Caesarean section in parturients with gestational hypertension. Can Anaesth Soc J 1980; 27: 389-94

4 Wilkinson P, Van Dyke C, Jatlow P, Barash P, Byck $R$. Intranasal and oral cocaine kinetics. Clin Pharmacol Ther 1980; 27: 386-94.

5 Fouz SE, Kotelko DM, Shnider SM, et al. Placental transfer and effects of cocaine on uterine blood flow and the felus. Abstract. Anesthesiology 1983; 59: A422.

6 Moore TR, Sorg J, Miller L, Key TC, Resnik R. Hemodynamic effects of intravenous cocaine on the pregnant ewe and fetus. Am J Obstet Gynecol 1986; 155; 883-8.

7 Woods JR, Plessinger MA, Clark KE. Effect of cocaine on uterine blood flow and fetal oxygenation. JAMA 1987; 257: 957-61.

8 Gross JR, Hartigan ML, Schaffer DW. A suitable substitutc for 4 per cent cocaine before blind nasotracheal intubation: $3 \%$ lidocaine- $0.25 \%$ phenylephrine nasal spray. Anesth Analg 1984; 63: 915-8.

9 Ramanathan $S$, Friedman $S$, Moss $P$, Arismendy $J$, Turndorf $H$. Phenylephrine for the treatment of maternal hypotension due to epidural anesthesia. Abstract. Anesth Analg 1984; 63: 262.
Résumé

On rapporte le cas d'une patiente àgée de 38 ans atteinte d'éclampsie devant subir une césarienne d' urgence et requérant une intubation nasotrachéale éveillée à cause d'une lacération et d' un oedème massif de sa langue. Une vasoconstriction átait requise a cause d'une thrombocytopénie. L'utilisation d'urte solution de lidocaïne à trois pour cent avec 0.125 pour cent de phénylephrine pour l'anesthésie et la vasoconstriction est décrite amenant une issue favorable tant maternelle que néanatale. 